\title{
The scientific committee of the International Medical Society of Paraplegia
}

It is for us a great pleasure to participate in this, the thirtieth anniversary number of Paraplegia.

The International Medical Society of Paraplegia (IMSOP) was launched by the late Sir Ludwig Guttmann, and two years later, its journal Paraplegia.

I wish to pay special homage to my friend, Phillip Harris the editor, and to say thank you to the current editorial secretary, Mrs Ann Scott. The journal goes from strength to strength with greater quality of articles, more issues - now 12 per year, more pages per issue, and innovations and improvements in the format.

Thirty years is a young age for our Society and its journal if one considers all of the tasks we must endeavour to foresee in the future, especially in the fields of prevention, pathophysiology, neurophysiology, treatment, restorative neurology (if possible, cure or partial cure), and rehabilitation.

A few years ago, it was decided to create within the IMSOP Council a scientific committee, whose main aims are to propose to Council and the general assembly relevant subjects for forthcoming meetings; and to organize appropriate lectures and/or seminars based on the progresses occurring in fundamental and in clinical research. Thanks to the International Spinal Research Trust, as part of the IMSOP 1991 scientific meeting, interest was focused on some of the fundamental aspects of neuronal re- generation. It was a great success, and the papers were published in Paraplegia.

Another of the scientific committee's tasks is to note and to report and comment on 'miraculous cures'. The late Sir George Bedbrook of Australia will always be remembered as a very active member; and also indeed as a personal friend.

Dr Iwatsubo of Japan has reported to our Society on the meeting arranged in Japan last year, by CIOMS, WHO, and UNESCO, on the subjects of genetics, ethics and human values.

Another information exchange has been with our American friends of ASIA (the American Spinal Injury Association). The IMSOP scientific committee has recently given its suggestions and comments concerning the standards for neurological classification, proposed by the ASIA committee, chaired by Dr J F Ditunno. It is hoped that through ASIA and IMSOP this classification will become an international tool, and will gather momentum.

We must all try to propagate worldwide our interests, and perfect our methodologies and their applications. Hopefully, in return, this will help us to evaluate the benefits which can be brought to our patients who have been afflicted by such a devastating injury.

Dr Paul Dollfus

Chairman of the scientific committee 